
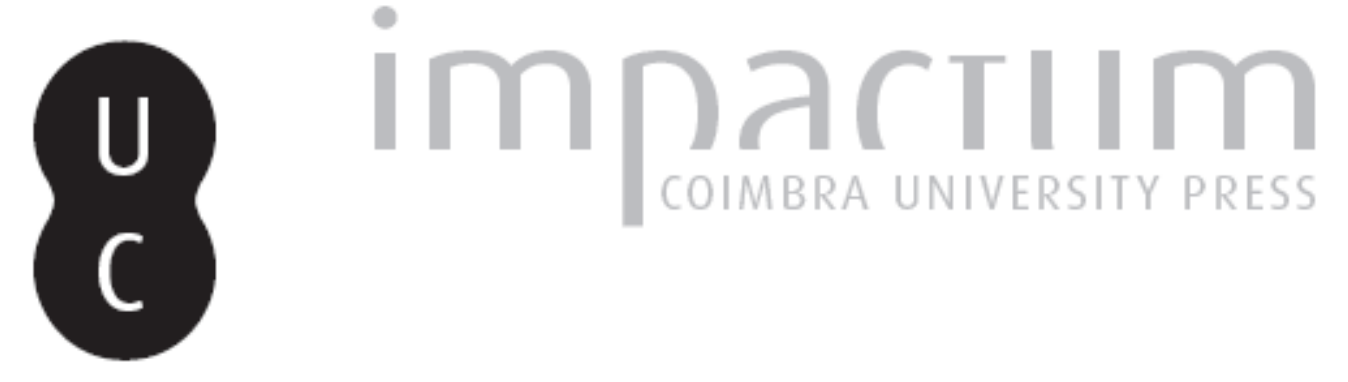

\title{
A docência e a investigação da história ultramarina na Faculdade de Letras da Universidade de Coimbra (1911-1974)
}

Autor(es): $\quad$ Santos, João Marinho dos Publicado por: Faculdade de Letras da Universidade de Coimbra, Instituto de História

URL

persistente:

DOI: $\quad$ DOI:http://dx.doi.org/10.14195/0870-4147_42_15

Accessed : $\quad$ 26-Apr-2023 04:18:38

A navegação consulta e descarregamento dos títulos inseridos nas Bibliotecas Digitais UC Digitalis, UC Pombalina e UC Impactum, pressupõem a aceitação plena e sem reservas dos Termos e Condições de Uso destas Bibliotecas Digitais, disponíveis em https://digitalis.uc.pt/pt-pt/termos.

Conforme exposto nos referidos Termos e Condições de Uso, o descarregamento de títulos de acesso restrito requer uma licença válida de autorização devendo o utilizador aceder ao(s) documento(s) a partir de um endereço de IP da instituição detentora da supramencionada licença.

Ao utilizador é apenas permitido o descarregamento para uso pessoal, pelo que o emprego do(s) título(s) descarregado(s) para outro fim, designadamente comercial, carece de autorização do respetivo autor ou editor da obra.

Na medida em que todas as obras da UC Digitalis se encontram protegidas pelo Código do Direito de Autor e Direitos Conexos e demais legislação aplicável, toda a cópia, parcial ou total, deste documento, nos casos em que é legalmente admitida, deverá conter ou fazer-se acompanhar por este aviso.

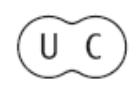





\title{
A docência e a investigação da história ultramarina na Faculdade de Letras da Universidade de Coimbra (1911-1974)
}

\author{
JoÃo Marinho dos SANTOS \\ Faculdade de Letras da Universidade de Coimbra \\ Centro de História da Sociedade e da Cultura - FLUC \\ uc3928@fl.uc.pt
}

\section{Resumo:}

Com base, sobretudo, nos "sumários" das cadeiras de História dos Descobrimentos/ História da Expansão e de História do Brasil, procurou-se reconstituir e caracterizar, no essencial, o que foi a docência e a investigação da História Ultramarina na Faculdade de Letras da Universidade de Coimbra e durante o período de 1911 a 1974 . O vector operatório do estudo pautou-se pela luta entre as designadas história tradicional e história científica e o resultado ou a conclusão final talvez seja poder-se inferir que a tradicionalidade dos Mestres de Coimbra residiu mais na utilidade (política) da história que ensinavam do que na ignorância da bibliografia nacional e estrangeira ou dos novos objectos e métodos historiográficos. A cruzada pelas "prioridades" das descobertas portuguesas e pelas "glórias nacionais" afinou, portanto, pelo que era considerado o interesse nacional e motivou círculos científico-culturais mais amplos que o escol encarregado da docência da História Ultramarina na Faculdade de Letras de Coimbra.

\section{Palavras chave:}

História tradicional; História científica; Prioridades geo-históricas; Direitos coloniais; Infante D. Henrique.

\section{Abstract:}

Based mainly on the 'lecture summaries' of the disciplines of History of the Discoveries/ History of Overseas Expansion and History of Brazil, we tried to recreate and characterize the teaching and research on Overseas History in the Faculty of Arts of the University of Coimbra, from 1911 to 1974 . The operative guideline for this study was the conflict between the so-called traditional history and scientific history. The final outcome or conclusion may be stated like this: the traditionality of the professors of Coimbra was attributable more to the (political) utility of the History they taught than to their ignorance of national and foreign bibliography or of the new historiographical objects and methods. Thus, the crusade in behalf of the "priorities" of the Portuguese discoveries and of the "national glories" was tuned with what they believed to be the national interest, and motivated much wider scientific and cultural circles than exclusively the elite in charge of teaching Overseas History in the Faculty of Arts of Coimbra

Keywords:

Traditional History; Scientific History; Geo-historical priorities; Colonial rights; Infante D. Henrique (Henry the Navigator). 
Com a criação da Faculdade de Letras de Coimbra, em 1911, a Licenciatura em Ciências Históricas e Geográficas ( $4 .{ }^{\circ}$ Grupo) não integrou a cadeira de História dos Descobrimentos, limitando-se os sumários de outras disciplinas, desse primeiro ano lectivo, a registar fugazes referências às "viagens marítimas". Porém, em 1913-1914, os "descobrimentos marítimos" já mereceram um considerável desenvolvimento na cadeira semestral de História Moderna e Contemporânea, com um particular relevo conferido à "questão das prioridades político-geográficas", matéria que mais adiante abordaremos.

Em 1921, com a reestruturação curricular da Faculdade de Letras de Coimbra, a História dos Descobrimentos passou a afirmar-se, então, como cadeira autónoma, ainda que de regime semestral. Foi seu primeiro titular o Professor Serras e Silva e o sumário de 1921-05-04 (sic) está redigido deste modo: "Programa de História dos Descobrimentos portugueses. As razões que permitiram a Portugal antecipar-se a outros países na via dos Descobrimentos". E sobre matérias das aulas seguintes: "Prioridade das descobertas portuguesas - Canárias, Madeira e Açores"; "Incapacidade política e social da Inglaterra para no começo do século XV se abalançar aos descobrimentos marítimos"; "Situação de Veneza e das repúblicas italianas, sua incapacidade para as descobertas..."; "Geograficamente a Espanha não tinha disposições marítimas com Portugal"; "Condições que tinha Portugal no começo do século XV favoráveis às descobertas"; "Qualidades do Infante D. Henrique para dirigir as expedições" sob a direcção de um Homem Providencial, predestinara o nosso País a realizar uma acção pioneira e praticamente exclusiva no âmbito das Grandes Descobertas dos séculos XV e XVI.

Assinale-se que, nos semestres de 1922 e de 1923, Serras e Silva voltará a insistir nas "Circunstâncias que permitiram a Portugal antecipar-se a outros povos na via das descobertas" e nas "Consequências [favoráveis] para Portugal e para o mundo das nossas descobertas", sem deixar de continuar a apresentar o Infante D. Henrique como "homem de génio e tenacidade e possuindo meios para aproveitar o momento". Sem obliterar o pendor nacionalista, contudo, em 1925, o programa de Serras e Silva para a cadeira de História dos Descobrimentos já adquire uma faceta (diríamos) mais antropológica e

\footnotetext{
1 Os sumários consultados estão no Arquivo da Universidade de Coimbra.
} 
sócio-cultural, designadamente com referências curiosas, entre outras, às: "Necessidades e mentalidade ou representação da vida na expansão dos povos"; "Mentalidades dos pastores e dos caçadores"; "Mentalidade guerreira dos portugueses nos começos do século XV - cavalaria e espírito de aventura"; “A Desordem na Índia - incapacidade dos governadores, ambição dos capitães, disseminação e grande afastamento das fortalezas, indisciplina dos soldados"... Enfim, quer no domínio dos temas, quer no dos métodos (ao reconhecer a importância do comparativo, a par do analítico e do sintético), Serras e Silva, entre 1921-1931, patenteou uma inegável evolução no magistério da História dos Descobrimentos. Mas, manteve-se fiel à moda historiográfica portuguesa de então.

Referimo-nos à "prioridade" das nossas descobertas ultramarinas e, para explicitar esta questão, permitimo-nos transcrever os critérios ou as "provas" esboçadas por um dos primeiros e, sem dúvida, dos maiores defensores desta pretensa glória nacional. Estamos a falar do Visconde de Santarém e a extrair da sua obra Demonstração dos Direitos que tem a Coroa de Portugal sobre os territórios situados na Costa Occidental d'Africa [...]: "As provas da prioridade de um descobrimento territorial são de duas naturezas, a saber: $1^{\circ}$, as que são atestadas pelas cartas geographicas e hidrographicas contemporaneas, onde os primeiros descobridores marcaram [com sinais heráldicos e/ou pavilhões, desenhados por cosmógrafos] esses descobrimentos que elles mesmos fizeram, e que foram depois copiados, generalizados, e seguidos ou admittidos por todas as nações marítimas; $2^{\circ}$ as que constam dos testemunhos e das relações dos Historiadores contemporaneos dignos de fé, e que são geralmente reconhecidos como authoridades historicas"2. Possivelmente (os seus sumários não são muito esclarecedores a este respeito), Serras e Silva utilizava, nas aulas, os dois tipos de provas ou de documentos. Mas, deixando, por ora, a persistência desta temática, passemos a tentar averiguar em que estádio científico se encontrava, em Portugal, a historiografia dos Descobrimentos e da Expansão Ultramarina.

Sob o título Evolução da Historiografia dos Descobrimentos Marítimos, a 25 de Outubro de 1952, Aristides de Amorim Girão, por impedimento de Damião Peres, lia a Oração de Sapiência que este se encarregara de proferir na abertura do respectivo ano académico. Eram ambos Doutores na Faculdade de Letras da Universidade de Coimbra. O primeiro doutorara-se, em 1922, em Ciências Históricas e Geográficas e, entre 1948-1951, leccionara a cadeira de Geografia Colonial Portuguesa, acabando por integrar, em 1957, a Secção de Ciências Geográficas da Junta das Missões Geográficas no Ultramar. O segundo

\footnotetext{
2 Ob.cit., Lisboa, Imprensa Nacional, 1855, pp. 4 e 11.
} 
já fora encarregado da regência da cadeira de História dos Descobrimentos e da Colonização, de 1933 a 1936 (sê-lo-ia, igualmente, entre 1939 e 1959), e, além de outros cargos, exerceria o de Director do Instituto de História Ultramarina, na Faculdade de Letras de Coimbra, em cuja sala do referido Instituto figura, aliás e muito justamente, um retrato seu ${ }^{3}$.

De pendor informativo e retrospectivo, a "Oração" de Damião Peres assinala que a historiografia dos Descobrimentos dos séculos XV e XVI, ainda que bem adornada de "pruridos eruditos" e de "feição épica", está eivada de confusões e lacunas. Segundo ele, no século XVII, avolumaram-se estes defeitos e, na centúria seguinte, a evolução estrutural também pouco se alterou. Concretamente, a reconstituição da Vida do Infante D. Henrique (1758), por Francisco José Freire, além de estar recheada de "discursos, supostamente ditos pelo Infante ou pelos seus servidores", obedecera, claramente, mais a "ornatos de eloquência" do que a princípios de natureza científica, sendo necessário esperar pelo "espírito novo" do século XIX (novo nas fontes informativas e novo nos temas preferidos) para que a nossa historiografia se regenerasse. Provas (publicações) reveladoras desse "espírito novo"?

Damião Peres refere, essencialmente, as seguintes: em 1811 surgira o primeiro volume da Colecção de notícias para a história das nações ultramarinas, editada pela Academia das Ciências de Lisboa, uma "corporação científica que neste despertar da historiografia ultramarina portuguesa desempenhou uma acção bem importante, na qual veio a ser secundada, desde 1840, embora com escasso âmbito cronológico, pela Associação Marítima e Colonial, e igualada mais tarde, desde 1876, pela Sociedade de Geografia de Lisboa”. E, a título exemplar, o orador destacava a publicação de o Roteiro de Goa a Suez, o Roteiro da Viagem de Vasco da Gama, a Crónica de Guiné, o Roteiro de Goa a Diu, Alguns Documentos da Torre do Tombo ou os Anais da Marinha Portuguesa. Porquê? Em seu entender, por se tratar de fontes históricas, correctamente "exumadas do tumular silêncio dos depósitos em que jaziam", e que haviam ocasionado o estudo individual de certos problemas nos primeiros decénios de Oitocentos. Que problemas?

Em primeiro lugar os que perseguiam uma finalidade político-diplomática, a saber: "[...] o desejo de reabilitar a prioridade dos feitos marítimos portugueses, opondo a verdade, documentadamente apurada, ou rácio-cinadamente esclarecida, às falsidades defendidas, intencional ou não intencionalmente, por autores estrangeiros, e aproveitadas, no plano das realidades internacionais,

3 Cf. Memoria Professorum Universitatis Conimbrigensis, 1772-1937, 7. . Centenário da Universidade de Coimbra, 1290-1990. 
pelas potências desejosas de justificar à luz da história as suas cobiças, quando não as explorações já praticadas relativamente a parcelas importantes do ultramar português, sobretudo na Senegâmbia e na Guiné"4. Eis historiograficamente relevada a questão das prioridades, com Peres a destacar, naturalmente, o empenho do Visconde de Santarém, expresso, por exemplo, na Memória sobre a prioridade dos descobrimentos portugueses na costa d'Africa ocidental (1841), logo melhorada e vertida para francês, como convinha. Mas, exemplar também quanto ao esforço de reabilitação da prioridade de outros feitos marítimos portugueses, fora do continente africano, será a publicação, ainda em 1841 , por Matos Correia, da Prioridade das descobertas feitas pelos portugueses nas costas orientais da América do Norte. Por sua vez, em 1875, Luciano Cordeiro apresentará, no Congresso dos Orientalistas, uma comunicação intitulada "De la part prise par les Portugais dans la découverte de l'Amérique", centrada na questão das navegações portuguesas pré-colombianas. A polémica envolvia a questão do eventual reconhecimento do litoral setentrional brasileiro por navegadores espanhóis, antes da viagem de Cabral, e ao assunto devotar-se-á, também, além de outros, o "Astrónomo-Historiador" Duarte Leite, datando de 1921 e 1923 alguns dos seus primeiros e mais válidos trabalhos no domínio da história, a saber: Os falsos precursores de Cabral; O mais antigo mapa do Brasil; e A exploração do litoral do Brasil na cartografia da 1. ${ }^{a}$ década do século XVI.

Ora, foi neste aro temporal (recorde-se) da década de vinte que Serras e Silva leccionou, convindo ter presente que, entre 1912 e 1924, ou seja, sobre o pano de fundo da participação de Portugal na 1. ${ }^{a}$ Grande Guerra (essencialmente para preservar os seus territórios ultramarinos), voltou a decorrer um activo período de reivindicação de prioridades e de exaltação das glórias nacionais. Estiveram, então, particularmente empenhados neste esforço Joaquim Bensaúde e Luciano Pereira da Silva, ambos ligados a Coimbra.

O último, Professor de Matemática na Universidade de Coimbra, centrará muitos dos seus estudos na astronomia e na ciência náutica portuguesa (entre 1913 e 1926 publicará 27 trabalhos, sobretudo no Boletim da Biblioteca da Universidade de Coimbra) e confessar-se-á particular amigo e admirador de Bensaúde, sendo este apreço mutuamente reconhecido. A propósito, registe-se que Luciano Pereira da Silva considerará Os falsos precursores de Álvares Cabral como o "trabalho mais notável" de Duarte Leite, ao lograr demonstrar,

4 Sobre a disputa territorial dos Europeus em África e, particularmente, sobre a posição portuguesa, veja-se, entre outros, Portugal na África Contemporânea, de Richard Pattee, Coimbra, Faculdade de Letras das Universidade de Coimbra, Instituto de Estudos Ultramarinos, 1959 e que constituiu dissertação de Doutoramento apresentada à referida Faculdade. 
através das "suas poderosas faculdades de análise e do seu grande saber matemático", que nenhum dos quatro precursores espanhóis (Hojeda, Pinzon, Lepe e Mendoza) esteve no Brasil antes de Pedro Álvares Cabral.

A cruzada do nosso pioneirismo descobridor foi particularmente reassumida por Joaquim Bensaúde, o qual, entre 1874 e 1884, viveu na Alemanha, mais propriamente em Hanover, por cuja Escola Técnica Superior se licenciou e, ali, tomou contacto com a obra do insigne cientista alemão Alexander Humboldt, designadamente com os seus estudos intitulados Cosmos, Exame Crítico da História da Geografia do Novo Mundo, e Progressos da Astronomia Náutica nos Séculos XV e XVI. Humboldt procurou demonstrar, nesses estudos, a ignorância dos marinheiros portugueses da Época das Grandes Descobertas, contrapondo-lhe os conhecimentos náuticos dos alemães, particularmente os de Martinho da Boémia. Este chegou ao nosso País por volta de 1484, mas, por esta altura (e é uma indiscutível contraprova), já os portugueses estavam Às portas da Índia, ou seja, já navegavam no Atlântico Sul, e, tanto quanto se sabe, sem o apoio científico-técnico dos alemães ${ }^{5}$.

Joaquim Bensaúde, como se disse, decidiu-se a dar continuidade à causa que o Visconde de Santarém abraçara, porque a conjuntura voltava a ser de disputa internacional pelos territórios ultramarinos, não cessando de surgir, como ele dirá, "Les sucesseurs de Humboldt". A propósito, numa das suas cartas para Joaquim de Carvalho, datada de 6 de Fevereiro de 1931, Bensaúde haverá de comentar, uma vez mais, em tom de desabafo: "Vivemos n'uma época calamitosa. A obra demolidora de Humboldt enraizou-se em Portugal, domina entre nós a ânsia inconsciente e febril de deitar abaixo. A faina destruidora na história dos descobrimentos (o reflexo do que nos vinha do estrangeiro), tomou em Portugal um aspecto muito grave. Arrasou-se o saber dos nossos navegadores, desprestigiam-se as mais belas figuras nacionaes" ${ }^{\prime 6}$. Explicitemos, por interessar ao objecto e aos objectivos deste estudo, que a comunicação epistolar entre Bensaúde e o "Professor de Coimbra" Joaquim de Carvalho se explicam por este Mestre de Filosofia e da Cultura portuguesa, com magistério na Faculdade de Letras da Universidade de Coimbra, ter exercido o cargo de administrador da Imprensa da Universidade entre 30 de

5 Com base na Oração de Obediência, pronunciada por Vasco Fernandes de Lucena, em Roma a 11 de Dezembro de 1485, o "Comandante-Historiador" Fontoura da Costa, no estudo intitulado Às portas da Índia em 1484, analisou a hipótese de os Portugueses terem então chegado ao "Promontorio Prasso", nas proximidades de Moçambique. Cf., a propósito, de João Marinho dos Santos e José Manuel Azevedo e Silva, A Historiografia dos Descobrimentos através da correspondência entre alguns dos seus vultos, Coimbra, Imprensa da Universidade, 2004.

6 In A Historiografia dos Descobrimentos..., p. 249. 
Julho de 1921 e 30 de Junho de 1934. Em intensa actividade editorial, Carvalho fomentou a publicação, além de outras, de uma Colecção de Documentos para a História da Expansão Ultramarina dos Portugueses, convindo recordar que não era então fácil proceder à impressão de manuscritos em Portugal, por razões financeiras e de atraso tecnológico. Terá nascido, assim, por esta altura, uma sólida amizade entre estes dois "notáveis" da cultura portuguesa, já que, através da Imprensa da Universidade, Bensaúde logrou ver publicados alguns dos seus tão anelados estudos, como: Les legendes allemandes sur l'histoire des découvertes maritimes portugaises: deuxiéme partie (Coimbra, Imprensa da Universidade, 1927); Origines du plan des Indes: études sur l'histoire des découvertes maritimes (Coimbra, Imprensa da Universidade, 1929); Lacunes et surprises de l'Histoire des Découvertes Maritimes: 1. partie (Coimbra, Imprensa da Universidade, 1930).

Em conclusão: o círculo científico - cultural da Faculdade de Letras da Universidade de Coimbra, particularmente através da Imprensa da Universidade e de Joaquim de Carvalho seu director, pelos anos 20 e 30 do século XX, reassumira, também, por razões políticas, a cruzada publicitária das "prioridades portuguesas" no âmbito das Grandes Descobertas dos séculos XV e XVI. Naturalmente, Serras e Silva ampliava, nas suas aulas de História dos Descobrimentos, tão apaixonadas polémicas e tão propalados estudos, sobretudo os da autoria de Bensaúde. Foi tão impressiva esta vivência no magistério Coimbrão que, mesmo minguando conjunturalmente a pressão política, persistirá esta curiosidade histórica. Concretizemos.

A partir de Janeiro de 1934 (o último sumário da cadeira de História dos Descobrimentos assinado por Serras e Silva tem a data de 1933-06-01), Manuel Lopes de Almeida, Licenciado em Ciências Históricas e Geográficas e Doutorado pela Universidade de Coimbra em 1940, ainda que professo duma "Renovação da História dos Descobrimentos", manter-se-á fiel ao magistério científico-diplomático do Visconde de Santarém, de Luciano Cordeiro, de Joaquim de Bensaúde, de Luciano Pereira da Silva e de outros adeptos das "prioridades portuguesas". Consequentemente, destacará, nos sumários da referida cadeira, como excrescências ou "falsidades" de A história tradicional:

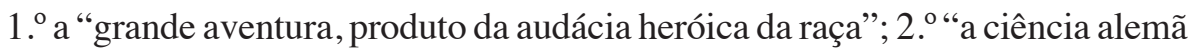

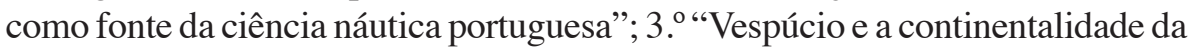
América"; 4. "Brasil descoberto por acaso"; 5. "Portugal não fez navegações para Ocidente."

O Professor Doutor Manuel Lopes de Almeida não dedicou a maior parte do seu labor de investigador à História Ultramarina, mas, mesmo assim, pertencem-lhe trabalhos como: "Duarte Lopes explorador do Congo" (Biblos, 
3, 1927, pp. 582-593); “Subsídios para a história ultramarina no século XVII. I - Carta Geral dos servidores do Estado da Índia em 1635. II - Carta de Pedro Roiz Botelho, capitão de Mombaça" (Biblos, 9, 1933, pp. 184-191); "Domínio ultramarino. Domínio português na África" in História de Portugal, dir. de Damião Peres (Barcelos, Portucalense Editora, 1935, vol. 7, pp. 563-606); Manuel de Abreu Mousinho - Breve discurso em que se conta a conquista do Reino do Pegú (Barcelos, Portucalense Editora, 1936, XXIII+71 p.); "Um documento sobre a expedição de Duclerc ao Rio de Janeiro em 1710" (Boletim da Biblioteca da Universidade de Coimbra, 19, 1950, pp. 383-391); Notícias históricas de Portugal e Brasil (1715-1750 e 1751-1800), 2 vol. [em col.] (Coimbra, 1961-1964) ${ }^{7}$. Retenha-se, ainda, que foi vogal do Centro de Estudos Históricos Ultramarinos a partir de 1956 e que, juntamente com Idalino Ferreira da Costa Brochado e António Joaquim Dias Dinis, integrou a "subcomissão" da publicação dos Monumenta Henricina (Coimbra, 1960-1974).

Após a fugaz passagem de Lopes de Almeida pelo magistério da História Ultramarina, nos anos lectivos de 1934-1935 e 1935-1936 Vergílio Guerra Taborda responsabilizou-se pela leccionação da então designada cadeira de História dos Descobrimentos e da Colonização Portuguesa e também ele concordará em considerar o Visconde de Santarém, Luciano Cordeiro, Sousa Viterbo, Joaquim Bensaúde e Luciano Pereira da Silva, entre outros, como representantes nacionais da "renovação moderna da história dos descobrimentos...”. Porém, Vergílio Taborda já ousa criticar (e com alguma justeza, diga-se) a tese de Joaquim Bensaúde quanto à "origem do plano das Índias", por evidente anacronismo, pelo menos no que à "Índia Oriental" dizia respeito, e já confere um desenvolvimento particular a matérias relativamente novas, como a navegação astronómica, a política nacional do sigilo (a que nos referiremos) ou a cartografia dos Descobrimentos.

Porém, não lograva unanimidade o seu parecer sobre aquela plêiade de historiadores ter concorrido para a "renovação moderna da história dos descobrimentos". Antes pelo contrário. A cruzada de Bensaúde já havia tempo que vinha sendo considerada, por alguns influentes e notáveis portugueses, como sendo exagerada. Mais: temia-se que o seu tradicionalismo historiográfico continuasse a embargar o passo ao imprescindível exame crítico das fontes históricas e à modernidade metodológica. Esta questão não era de somenos importância, uma vez que a historiografia portuguesa se havia associado muito

7 Publicações dos Professores da Faculdade de Letras, Coimbra, Faculdade de Letras da Universidade de Coimbra, 1974,pp. 17-29 e Memoria Professorum Universitatis Conimbrigensis, 1772-1937,pp. 66-67. 
de perto, como vimos dizendo, à defesa do que era considerado o interesse nacional. Por outras palavras, se se pretendia um almejado "progresso nacional", não se podia aceitar que o "tradicionalismo" vingasse, em particular através da história como forma de registo do passado. Era pertinente esta justificação? Era. E era inteiramente justa a crítica dirigida aos tradicionalistas? Registemos, a propósito, a opinião de Luciano Pereira da Silva. Para este, Joaquim Bensaúde era "o benemérito, e nunca assaz louvado investigador da nossa história náutica", jamais, porém, o "amor da verdade", como princípio sagrado, se deveria subalternizar ao "gôsto de louvar a gente da nossa terra". E, para justificar que não tinha dúvidas "em fazer reivindicações de sentido inverso ao das glórias portuguesas", propunha que os peninsulares ibéricos se inspirassem "no estudo dos documentos existentes nos dois países, [de que] resultará farta glória para ambos os povos, tanto maior quanto melhor fundamentada"8.

De qualquer modo, invoque-se que, em 1911, havia-se formado a Associação Cultural "Renascença Portuguesa" e, no ano seguinte, o "Médico-Historiador" Jaime Cortesão passara a dirigir A Vida Portuguesa, uma publicação periódica (quinzenal) que pretendia fazer um "inquérito à vida nacional", ou seja, às potencialidades anímicas da sociedade lusa ${ }^{9}$. É que, neste círculo científico-cultural, acreditava-se na acção cívica dos "homens superiores", capazes e dispostos a levedarem a grande massa social, muito embora não lograsse unanimidade a adopção da estratégia mais adequada para se alcançar o progresso colectivo. Assim, em particular o "nacionalista e técnico-funcionalista" (como era classificado) António Sérgio não compreendia, segundo outros associados, a participação do "sentimento" no processo do conhecimento, acabando por despojar o real do "dinamismo psíquico” tão enfatizado por Antero de Quental. Ao lado de Sérgio, Raul Proença era outro dos que clamavam que a tradição (ou antes, o tradicionalismo) não servia para nada e que, concretamente, a história não tinha eficácia científica, só servindo para memória. Ao invés, Jaime Cortesão e Teixeira de Pascoais, por exemplo, retorquiam que o tradicionalismo só preconizava o regresso "às fontes originárias da vida para crear uma nova vida".

Esta polémica teve, porém, o mérito de estabelecer a cesura entre a "história-memória" e a "história científica", acabando por trazer, ainda que tardiamente, alguns espíritos críticos ao campo da historiografia. Foi o caso de Duarte Leite,

8 "Pedro Nunes espoliado por Alonso de Santa Cruz", in Obras Completas de Luciano Pereira da Silva, vol. III, Lisboa, Agência Geral das Colónias, 1946, pp. 163-184.

9 Cf. João Marinho dos Santos, "Notas para o (re)conhecimento de Jaime Cortesão", Cadernos da Revista de História Económica e Social, Lisboa, Sá da Costa Editora, 1985, pp. 49-78. 
entre outros, devendo-se muito do seu contributo científico à preocupação com a dúvida metódica e com a inquirição sistemática das fontes, ou seja, com a sua persistente sujeição à crítica, para não se (re)criarem autênticas "falsidades", conforme se comprova (também) pelo seu epistolário com Joaquim de Carvalho $^{10}$. Mais preciso, porém, é no artigo intitulado "Talent de bien faire", redigido com a finalidade de comentar a conferência de Joaquim Bensaúde sobre as Origines du plan des Indes. Duarte Leite, se lhe reconhece o mérito de ter conseguido demonstrar, perante "a severa crítica alemã", que a "sciência náutica portuguesa no Renascimento [...] não dimanou da Alemanha, como sustentaram Humboldt e na sua esteira todos os autores, mas exclusivamente de astrónomos ibéricos e de marítimos portugueses", não deixará de o criticar por deformar a imagem do Infante D. Henrique, indo a reboque da tradição $o^{11}$.

Também reveladora da atitude bastante crítica (no bom sentido) de Duarte Leite se nos afigura a polémica sobre a designada teoria do sigilo nos Descobrimentos Portugueses, uma construção de Jaime Cortesão. Frontal e abertamente, o "Astrónomo-Historiador" do Porto (referimo-nos a Leite) haverá de declarar que tal teoria estava construída "sobre textos indevidamente invocados ou interpretados tendenciosamente, sobre factos de diverso significado, e por vezes sobre conjecturas fantasiosas" 12 . Ora, um dos que se perfilaram a seu lado nesta (mas só nesta) apreciação foi Álvaro Júlio da Costa Pimpão, Professor da Faculdade de Letras da Universidade de Coimbra, ao apresentar, em 1938, no $1 .^{\circ}$ Congresso da História da Expansão Portuguesa no Mundo, realizado em Lisboa, uma comunicação sob o título A historiografia oficial e o sigilo sobre os descobrimentos. Costa Pimpão contrariava, abertamente, Cortesão, quando este pretendia defender que as crónicas portuguesas da época dos Descobrimentos tinham sido truncadas ou obliteradas por razões político-diplomáticas ${ }^{13}$.

A mesma concordância, entre Leite e Pimpão, já se não verificou no que concerne à obra, de Gomes Eanes de Zurara, Crónica dos feitos da Guinee. Em concreto, Álvaro Pimpão defendera, em 1926, que Zurara escrevera não uma única, mas duas obras, a saber: uma Crónica ou Livro dos feitos do Infante

${ }^{10}$ Cf. A Historiografia dos Descobrimentos...

${ }^{11}$ Talent de bien faire: a propósito da conferência de Joaquim Bensaúde - "Origines du plan des Indes, Paris, Librairie Aillaud, 1929, 32p. Na impossibilidade formal de desenvolvermos esta questão, aqui, remetemos para o estudo A Historiografia dos Descobrimentos.

${ }^{12} \mathrm{O}$ sigilo, in Duarte Leite - História dos Descobrimentos. Colectânea de esparsos. Organização, notas e estudo final de V. Magalhães Godinho, Lisboa, Ed. Cosmos, 1958, Vol. I, pp. 411-449.

${ }^{13}$ Cf. A Historiografia dos Descobrimentos... 
[D. Henrique] e uma Crónica dos feitos da Guiné; a primeira escrita, segundo ele, entre 1464 e 1468 (embora, por argumentos, de crítica interna, se inclinasse para 1464) e a segunda entre 1452 e $1453^{14}$. Por sua vez, Duarte Leite discordava das datações propostas por Pimpão, mas, mais ainda, por ele alinhar com Joaquim Bensaúde quanto ao excessivo relevo conferido ao espírito de "cruzada" (ao valor da honra) manifestado na acção e no pensamento do Infante, esquecendo, quase por completo, o apego deste, igualmente, à "mercancia" (ao valor do proveito).

Independentemente do posicionamento historiográfico (naturalmente, também, ideológico) destes e de outros autores portugueses, o que estas polémicas perseguem é a preocupação em conferir à história um maior carácter científico. Foi o caso do então jovem historiador Vitorino Magalhães Godinho, ao publicar, em 1943, um trabalho sobre Dúvidas e problemas àcêrca de algumas teses da história da Expansão, em que, pese embora reconhecer que o Visconde de Santarém e Joaquim Bensaúde haviam representado "os dois marcos desse esforço de reivindicação do património nacional", lembrará que o "trabalho do historiador não termina com a leitura e transcrição da fonte [histórica], começa então (o que de modo algum significa que o trabalho de ler e transcrever seja menos meritório)". Começa (dirá Godinho) com a construção das fontes em concordância com as curiosidades e os problemas postos pelo historiador; com a interpretação dos factos assente na fundamentação das fontes; com a importância conferida às conjunturas e às estruturas e não tanto aos acontecimentos; ou com a inventiva de ler originalmente os documentos ${ }^{15} \ldots$

Perguntemos, agora, pela ressonância desta cruzada científica na Faculdade de Letras de Coimbra e, mais particularmente, no que à docência e à investigação da História Ultramarina dizia respeito.

Na já citada Oração de Sapiência para inaugurar o ano lectivo de 1952-1953, Damião António Peres afirmava-se como defensor de uma história feita com fontes novas (inéditas), diversificadas e correctamente transcritas, que concorressem tanto para "publicações documentais como para a elaboração de monografias e obras gerais" de carácter problematizador, ou seja, uma história bem enraizada num quadro geográfico económico e científico, sem obliterar (antes pelo contrário) os valores mais espirituais do homem e dos homens. Cumpriu? Além da memória do seu atraente magistério, Peres deixou-nos, de facto, um conjunto de valiosas obras de investigação histórica, particularmente

${ }^{14}$ A “Crónica dos feitos da Guinee" - As minhas "teses" e as "teses" de Duarte Leite, Biblos, vol. XVII, t. V, Coimbra, 1941, 36p.

15 Cf. A Historiografia dos Descobrimentos... 
no domínio da História dos Descobrimentos. Citaremos: A Madeira sob os donatários (Funchal, 1914); História dos descobrimentos portugueses (Porto, 1943); Sentido universal da expansão portuguesa (Rio de Janeiro, 1951); Pedro Álvares Cabral e o descobrimento do Brasil (Porto, 1959); Uma prioridade portuguesa contestada mas incontestável: a circum-navegação da África austral por Bartolomeu Dias (Lisboa, 1960). E destacaremos, a par da sua valiosíssima História dos descobrimentos portugueses, a monumental História de Portugal, que o público se habituou a apelidar de Edição de Barcelos. Damião Peres surge como Director Literário da publicação (a Direcção Artística foi confiada a Eleutério Cerdeira) e logrou mobilizar a colaboração de 27 autores, entre eles geógrafos, arqueólogos, filólogos, juristas, médicos, filósofos e, claro está, historiadores. Citemos, entre os mais distintos colaboradores, os nomes de Mendes Correia, Aarão de Lacerda, Vergílio Correia (Professor da Faculdade de Letras de Coimbra), David Lopes e Manuel Ramos (igualmente Professores desta Faculdade), Paulo Merêa, Jaime Cortesão, António Baião, Hernâni Cidade, Joaquim de Carvalho, Lopes de Almeida ou Marques Guedes. Os vários volumes da primeira fase desta publicação saíram entre 1928 e 1954.

Damião Peres jubilou-se em 1959 e, naturalmente, fez escola, motivando, até, colegas estranhos à área da História Ultramarina. Foi o caso do Doutor Torquato Brochado de Sousa Soares. Em 1961 e em O Instituto - Revista científica e literária (Coimbra, número comemorativo do $\mathrm{V}$ centenário da morte do Infante D. Henrique, pp. 21-51), Torquato Soares, sob o título "O Infante D. Henrique Arauto da Idade-Nova", publicará um artigo que contém, igualmente, a seguinte profissão científica: "Ora, ao historiador cumpre a missão de explicar, isto é, de esclarecer - e o esclarecimento não se compadece com a formulação de conceitos que, por muito aliciantes que sejam, carecem de solidez". Eis claramente definida a necessidade do recurso à conceptualização operativa, sugerida pelas fontes (e não pela subjectividade do historiador), se se pretende fazer história científica. É verdade que o estudo de Torquato Soares tem por objecto um tema (assinale-se) recorrente da historiografia nacional, mas reconstrói-o, recorrendo a uma metodologia global ("entrelaçando factores de ordem religiosa ou simplesmente espiritual com factores de ordem material)", utilizando autores e estudos inovadores (como os de Michel Mollat, F. L. Ganshof, Charles Verlinden e Henri Pirenne), inquirindo as fontes históricas e elaborando uma explicação/compreensão lógica (ainda que discutível). Sendo embora, essencialmente, um medievalista, Torquato Soares, já em 1960, redigira um artigo "Acerca da chamada Crónica dos feitos da Guiné, de Gomes Eanes de Zurara" (Revista Portuguesa de História , 9, 1960, pp. 287-302). Deverão, ainda, ser referidos outros trabalhos seus no domínio da História Ultramarina, a saber: 
"Algumas observações sobre a política marroquina da monarquia portuguesa" (Revista Portuguesa de História, 10, 1962, pp. 509-554); “Um homem e uma data: Pedro Álvares Cabral, 1500” (Estudos Humanísticos, 2, 1971, pp. 241-260); "A marinha portuguesa: sua contribuição para o robustecimento da independência e expansão nacional em África. Significado das viagens de Diogo Cão" (Estudos Humanísticos, 2, 1971, pp. 35-64) ${ }^{16}$.

Não era, portanto, por via dos trabalhos destes historiadores conimbricenses que persistia e predominava em Portugal, como insistirá em 1963 Frédéric Mauro, uma história de tipo tradicional. O Historiador francês classificava-a deste modo, por ignorar a bibliografia estrangeira, por mostrar um interesse quase exclusivo pelos problemas nacionais, por revelar um enorme desconhecimento das outras ciências sociais, e por se deleitar com a "erudição pela erudição"17.

Mauro encomiava, no entanto, que a docência e a investigação da História, em Portugal, estivessem centradas em "Institutos"; que houvesse um número razoável de "publicações periódicas"; e que fossem de grande mérito algumas colecções "não periódicas", como as da Agência Geral do Ultramar, da Junta de Investigações do Ultramar e do Centro de Estudos Históricos Ultramarinos. Mais: em seu entender, não faltavam os guias e os instrumentos de trabalho, persistindo o gosto pela realização de colóquios e congressos, como o "Congresso de História da Expansão Portuguesa no Mundo" (Lisboa, 1938), o "Congresso do Mundo Português" (Lisboa, 1940), o "Congresso Luso-espanhol para o progresso das Ciências" (Coimbra, 1956) e o "Congresso do Quinto Centenário do Infante D. Henrique" (Lisboa, 1960).

A estes eventos poderíamos acrescentar a produção de obras verdadeiramente monumentais, como a História da Colonização Portuguesa do Brasil (direcção e coordenação literária de Carlos Malheiro Dias, direcção cartográfica do Conselheiro Ernesto de Vasconcelos e direcção artística de Roque Gameiro, Porto, Litografia Nacional, [1924]) ou os Portugaliae Monumenta Cartographica (Lisboa, 1960, sob a direcção de Armando Cortesão e Avelino Teixeira da Mota). Engenheiro Agrónomo de profissão e irmão de Jaime Cortesão, Armando Cortesão iniciou-se na investigação histórica com o estudo Subsídios para a história do descobrimento da Guiné e de Cabo Verde e, em 1969 e 1970 (neste ano, com a colaboração de Luís de Albuquerque), dará à estampa os dois preciosos volumes da História da Cartografia Portuguesa.

\footnotetext{
${ }^{16}$ Publicações dos Professores da Faculdade de Letras, Coimbra, Faculdade de Letras da Universidade de Coimbra, 1974, pp. 491-507.

17 "L'orientation actuelle des études historiques - l'histoire au Portugal", n. ${ }^{\circ} 466$ da Revue Historique, Paris, Abril-Junho, 1963, pp. 433-442.
} 
Já, em 1961, por proposta da Faculdade de Ciências de Coimbra, recebera o grau de Doutor Honoris Causa, além do mais por dirigir uma secção do "Agrupamento de Estudos de Cartografia Antiga".

Mas, regressemos à questão da cientificidade da história que era ensinada e investigada no nosso País, em particular na Faculdade de Letras da Universidade de Coimbra.

Do programa do Prof. Doutor Salvador Dias Arnaut, para a cadeira de História dos Descobrimentos, no ano lectivo de 1957-1958 (primeiro semestre, já que o segundo teve a orientação de Damião Peres), ressalta, de facto, a persistência de temas tradicionais, bem evidenciada nos seguintes registos: "Viagens portuguesas trecentistas às Canárias"; "Vocação marítima de Portugal"; "Acção do Infante D. Henrique"; "Viagens para a Madeira"; "Ultrapassagem do Bojador"; "Reconhecimento da costa africana"... Vislumbra-se, ainda, uma clara preocupação com a reconstituição histórica e não tanto com a sua compreensão e explicação.

Já Luís Ferrand de Almeida, ao substituir Dias Arnaut na orientação da História dos Descobrimentos, durante o primeiro semestre do ano lectivo de 1958-1959, procurará introduzir um espectro mais alargado dos temas e, consequentemente, romper com a tradicionalidade. Concretamente, o quadro das origens (remotas) do movimento expansionista português surge inovado com referências (caracterizadoras) ao "renascimento europeu a partir do século XI", sob duas perspectivas: a do "embate religioso-civilizacional Cristandade-Islam" e a das "tentativas de expansão pelo Atlântico" antes da presença portuguesa. Só depois surge o tema da "Génese dos descobrimentos portugueses", segundo uma abordagem não só geo-histórica, mas também antropológica ou étnica, que conflui na (tradicional) "Vocação marítima de Portugal". Mais: ainda no âmbito da "Génese dos descobrimentos portugueses", Ferrand de Almeida confere particular importância às componentes mercantil (comércio interno e externo), técnica ("desenvolvimento da marinha" portuguesa), religiosa (destaque para o "espírito" de cruzada), científico-cultural (com relevo para a "cultura náutica") e social (evidenciando o papel da burguesia comercial). Concluirá esta unidade programática com a lógica "Diversidade dos factores da expansão".

Apetece afirmar que o magistério de Ferrand de Almeida persegue outra história e pertence a outra historiografia, já que, em contraponto (sem lhe retirar, antes pelo contrário, mérito científico), Damião Peres irá insistindo, durante os segundos semestres e até à sua jubilação em Julho de 1959, na "definição diplomática dos direitos de exploração na costa e mares africanos" e na reconstituição das viagens de Diogo Cão e Bartolomeu Dias, a par de outros périplos de curto raio a cargo dos portugueses. Ou seja, continuava apegado à 
prioridade das descobertas ou ao pendor nacionalista da nossa historiografia, como este sumário claramente evidencia: "descobrimento da Guiné hoje ainda portuguesa".

Com a jubilação de Damião Peres, Luís Ferrand de Almeida não só assegurou, por inteiro, a regência da História da Expansão Portuguesa, como pôde voltar a conferir ao respectivo programa uma visão mais inovadora, sem contudo prescindir da abordagem de algumas tradicionais unidades programáticas. Concretizando o suficiente, ao abordar "O renascimento europeu a partir do século XI", Ferrand introduz "Noções geográficas legadas pela Antiguidade à cultura medieval sobre a África atlântica" e, na "Génese dos descobrimentos portugueses", já contempla a investigação de Jaime Cortesão, referindo "Os factores geográficos e a "convergência atlântica" ou "A evolução do litoral português - sua importância histórica". O docente demonstrava estar a par da evolução da historiografia nacional, ao passar, por exemplo, em revisão crítica, a "lenda infantista" (Escola de Sagres e a pretensa grande cultura científica do Infante) e a "lenda anti-infantista" (cotejando posições de Joaquim Bensaúde, Duarte Leite e António Sérgio). E, ainda, outro exemplo: quanto "às causas de a conquista de Ceuta", ao invocar "Explicações" várias, entre as quais as de Oliveira Martins, Bensaúde, Sérgio, Cortesão e Vitorino Magalhães Godinho.

Consequentemente, a investigação de Ferrand de Almeida reflectirá, já neste período, um pendor inovador, bastando invocar alguns dos seus principais trabalhos científicos (só até 1974): A diplomacia portuguesa e os limites meridionais do Brasil, vol. I [1493-1700] (Coimbra, Instituto de Estudos Históricos Dr. António de Vasconcelos, 1957, 585 p.); "Vespúcio e o descobrimento do Rio da Prata" (Revista Portuguesa de História, 11, 1964, pp. 16-60); "Plantas do Oriente no Brasil em fins do século XVII" (Colóquio, 36, 1965, pp. 52-54); A Colónia do Sacramento na época da Sucessão de Espanha (Coimbra, Instituto de Estudos Históricos Dr. António de Vasconcelos, 1973, XVIII+538 p. $)^{18}$

A partir do segundo semestre do ano lectivo de 1961-1962, Salvador Dias Arnaut (que entretanto se doutorara) passa a titular da cadeira de História da Expansão Portuguesa, evidenciando, então, uma maior actualização, se tivermos em conta as referências às "opiniões" de Jaime Cortesão e de Dias Dinis (sem esquecer as de Damião Peres), ou a relevância conferida à

${ }^{18}$ Publicações dos Professores da Faculdade de Letras, Coimbra, Faculdade de Letras da Universidade de Coimbra, 1974, pp. 12-16. 
construção naval, às viagens marítimas e à cartografia nos séculos XV e XVI. Manterá a titularidade até 1974 , tendo a assessorá-lo, nos três últimos anos, a Licenciada Maria Áquila Neves dos Santos, a quem confiou as aulas práticas.

Já no que concerne à sua investigação, é sabido que as obras cientificamente mais relevantes de Salvador Dias Arnaut se situam no âmbito da Medievalidade, sendo justo enaltecer os estudos sobre A batalha de Trancoso (Coimbra, Instituto de Estudos Históricos Dr. António de Vasconcelos - Faculdade de Letras, 1947) e A crise nacional dos fins do século XIV: A sucessão de D. Fernando (Coimbra, Instituto de Estudos Históricos Dr. António de Vasconcelos - Faculdade de Letras, 1960). Esta última, porém (em nosso entender), configura e explicita, com admirável clareza e inquestionável rigor, o quadro emergente do interesse nacional pela conquista de Ceuta e, consequentemente, assinala o início do processo expansionista português. Explicitemos.

Foram, com efeito, aspirações de coesão político-social, de interesse pela independência nacional e de solução para a crise económico-financeira da "Longa Depressão" do século XIV e da primeira metade do seguinte que se constituíram como objectivos vitais dos que queriam ser portugueses e, por tal, escolheram um rei espúrio, mas que era uma alternativa à ameaça de ter como soberano D. João I de Castela. Tendo sido assim, a comparticipação historiográfica de Dias Arnaut é valorosíssima, lembrando nós que, estrategicamente, Ceuta (ou antes, a constituição de um senhorio real no Norte de África) foi a solução dificilmente encontrada para satisfazer aqueles objectivos nacionais. Enfim, A crise dos fins do século XIV-A sucessão de $D$. Fernando é livro de estudo obrigatório para quem quiser compreender as origens do processo expansionista português, ainda que, eventualmente, esta finalidade não tivesse presidido à investigação de Salvador Dias Arnaut.

Nos anos lectivos 1960-1961 e 1961-1962, Luís Ferrand de Almeida orientou, na Faculdade de Letras da Universidade de Coimbra a cadeira semestral de História do Brasil. Do respectivo programa consta a inventariação das características geográficas da ex-colónia portuguesa e a abordagem histórica da questão polémica do seu descobrimento (sem esquecer as viagens anteriores à de Cabral). As explorações geográficas dos primeiros anos de Quinhentos, o interesse pelo comércio do pau-brasil, a participação privada e oficial quanto ao esforço colonizador (traduzido, designadamente, no regime das capitanias e na sua substituição por um Governo Geral) foram alguns outros temas focados. Retenha-se que Ferrand de Almeida tenta a caracterização jurídica, social e até moral de algumas individualidades primeiras que se distinguiram na colonização brasileira, a par da abordagem do funcionamento das instituições político-administrativas. Enfim, pelos seus sumários cuidados e bastante analíticos, 
facilmente se capta a preocupação em descrever e qualificar a acção individual e colectiva dos agentes da história.

Em 1962-1963, a cadeira de História do Brasil foi orientada por Temístocles de Linhares e, pelos registos dos sumários (a cadeira era semestral), o respectivo programa patenteia uma maior participação da componente antropológica (física e cultural), pouco usual até então. Com efeito, matérias como as relações inter-tribais dos índios, as "condições em que se processou a miscegenação de aborígenes, negros e brancos" ou a "assimilação" e a escravização no Brasil colonial integram vários sumários, sem deixarem de persistir temas tradicionais, como o descobrimento do Brasil, o "bandeirismo" ou a "inconfidência Mineira".

Os sumários referentes ao ano de 1963-1964, assinados por Guilhermino César da Silva, voltam a revelar um maior interesse pelo descobrimento e povoamento do Brasil, pela colonização centrada na descoberta e exploração do ouro (obliterando, aparentemente, a importância da cana do açúcar), pelo "bandeirismo" e pelo "processo da Independência"...

Mas, em 1964-1965, Guilhermino César da Silva já optou por uma leccionação de cariz mais sócio-cultural, desenvolvendo, durante a maior parte das aulas, a unidade didáctica "fixação e expansão da cultura portuguesa", em que surgem referências à escravatura, à vida administrativa até ao século XIX (com particular incidência no período Pombalino), à acção dos Jesuítas, ao "movimento academicista", à arquitectura colonial no Brasil...

Já Temístocles de Linhares, no ano lectivo de 1965-1966 (em regime também semestral), conferiu clara importância à "História do Brasil económico", privilegiando, na sua leccionação, temas como o "comércio do pau-brasil", o "comércio e indústria do açúcar", a importância do "tabaco e da criação de gado", o "ciclo do ouro e do diamante", o "ciclo do café" e o "ciclo industrial". Esclareça-se que estava, então, em voga a designada "história cíclica", com a aparente vantagem de se destacar a sucessão monocultural ou polarizadora da respectiva economia em termos de funcionamento do mercado externo, mas, claramente, deformadora da realidade, até porque o produto dominante num ciclo raramente desaparece no outro, como sucedeu, por exemplo, com o pau-brasil ou o açúcar.

No ano lectivo seguinte, mantiveram-se quer o mesmo docente, quer o mesmo programa, para, em 1967-1968, Salvador Dias Arnaut, sem deixar de fazer referências aos "ciclos" do pau-brasil, do açúcar, da "caça ao índio", do ouro de lavagem e do gado, voltar a insistir na descoberta e na construção do espaço da colónia brasileira e do seu funcionamento administrativo.

Também Guilhermino César da Silva, responsável pela cadeira de História do Brasil em 1968-1969 e 1969-1970, se preocupará com “a ocupação do 
espaço brasileiro", articulando "povoamento e processo económico", traduzido na persistente "história cíclica", ainda que o movimento das "bandeiras", a "colonização do Sul do Brasil" e a "incorporação das Missões Orientais do Uruguai no território brasileiro" tenham conferido alguma complementariedade à perspectiva central da "ocupação do espaço brasileiro".

Entre 1970 e 1974, o titular da História do Brasil foi o Doutor Salvador Dias Arnaut, tendo como assistente, a partir de 1971 a Licenciada Maria Áquila Neves dos Santos.

Reafirmar que Portugal Continental é um país geograficamente pequeno e naturalmente pobre é cair num lugar-comum, mas é, também, justificar a necessidade da Expansão Ultramarina, quer pela via das Conquistas (invoque-se a presença lusa no Norte de África e em importantes cidades do Oriente), quer pela via das Descobertas, quer mesmo da Emigração (oficialmente vituperada por prejudicar a Colonização). Por outras palavras, só crescendo no Ultramar Portugal logrou fazer frente a Leão-Castela (a maior ameaça para a sua independência) e garantir a sua sobrevivência, que não o seu enriquecimento. Este projecto com objectivos vitais estiolou em 1974, mas até lá não se encontrou alternativa política, pesem embora algumas críticas proferidas por "arbitristas" internos e "estrangeirados". Demos, por exemplo, o testemunho de D. Luís da Cunha, ao lastimar que o crescimento e o desenvolvimento do nosso País não tivessem um carácter mais endógeno, mas a conformar-se com a posse do Ultramar por ser, em linguagem popular, "todo o bem que a velha tem"19.

Compreende-se, assim, facilmente (cremos nós) a utilidade da história e da memória colectiva ao procurarem imprimir no consciente e no subconsciente da Nação, através de contínuas gerações, a importância do nosso Ultramar (mesmo que, eventualmente, já obliterado em parcelas importantes como o Brasil), quer em grandeza territorial (dizia-se que Angola era catorze vezes e meia maior que Portugal Continental), quer em riqueza (e lá vinha a "Índia" das especiarias). Consequentemente, o nosso "Império", tão cobiçado por algumas potências estrangeiras, tinha que ser, diplomaticamente, fundamentado na sua posse histórica (daí a invocação recorrente das "prioridades" das descobertas) e defendido, se necessário, militarmente.

A esta história e memória colectiva de interesse nacional atribuíram os críticos internos e externos o apodo de tradicional, ou seja, classificaram-nas de empecilho ao progresso tão necessário e desejado. De qualquer modo,

${ }^{19}$ Instruções inéditas de D. Luís da Cunha a Marco António de Azevedo, Lisboa, Academia das Ciências de Lisboa, Imprensa da Universidade de Coimbra, 1929. 
a docência e a investigação históricas tiveram, entre nós, importantes cultores tradicionalistas, mas, cientificamente, mais actualizados do que seria de supor. Pensamos ter justificado esta interpretação e, sem emitirmos qualquer juízo depreciativo (cabe ao historiador compreender e explicar, não lhe cabe julgar), não resistimos em transcrever este parecer de Pierre Chaunu: "Il est normal et sain que la recherche en science sociale obéisse à l'appel des courants et des besoins de la société civile" 20 .

Recebido em/Text submitted on: 12/07/2011 Aceite em/Approved on: 21/09/2011

${ }^{20}$ Pour l'Histoire, Paris, Librairie Académique Perrin, 1984, p. 75. 